\title{
ÚLCERA GÁSTRICA TEREBRANTE E PANCREATITE AGUDA PROVOCADAS POR TRICOBEZOAR
}

\section{GASTRIC ULCERAND ACUTE PANCREATITIS CAUSED BY TRICHOBEZOAR}

\section{Alvaro Queiroz de Godoy, TCBC-PR ${ }^{1}$ Rose Meire Albuquerque Pontes ${ }^{2}$ André Reichert da Silva Godoy ${ }^{3}$}

\section{INTRODUÇÃO}

Bezoar ("badzahr" de origem árabe) significa acúmulo, no tubo digestivo, de substâncias ingeridas voluntariamente como fibras vegetais ou sementes, cabelo, pedras, medicamentos e certas fórmulas lácteas muito concentradas ${ }^{1}$. Das complicações a mais comum é a obstrução. Apenas cerca de $10 \%$ dos pacientes apresentam úlceras gástricas devido ao aumento da secreção ácida, podendo haver perfuração em cavidade livre ou em vísceras vizinhas, particularmente sobre o pâncreas.

Considerando a baixa freqüência da úlcera gástrica terebrante e pancreatite provocadas por tricobezoar resolvemos publicar o presente caso.

\section{RELATO DO CASO}

I. S. L., 14 anos, feminina, foi atendida com quadro de dor epigástrica intensa, febre e vômitos com evolução de cinco dias. Havia história de desorganização familiar e hábito de tricofagia, além da ingestão de objetos como brinquedos de plástico. Encontravase em regular estado geral e apresentava "massa" endurecida na região epigástrica, de aproximadamente $25 \mathrm{~cm}$, pouco móvel e dolorosa. As radiografias do abdome foram normais e entre os exames laboratoriais apenas a amilasemia encontrava-se elevada em duas dosagens. A ultra-sonografia mostrou "massa" na região epigástrica, a endoscopia foi inconclusiva pela presença de grande quantidade de resíduos no estômago e a tomografia também evidenciou "massa" gástrica intraluminal sugestiva de bezoar. A paciente foi submetida à laparotomia que confirmou a presença de grande tricobezoar gástrico, retirado por gastrotomia anterior, com peso de $820 \mathrm{~g}$ (Figura 1).

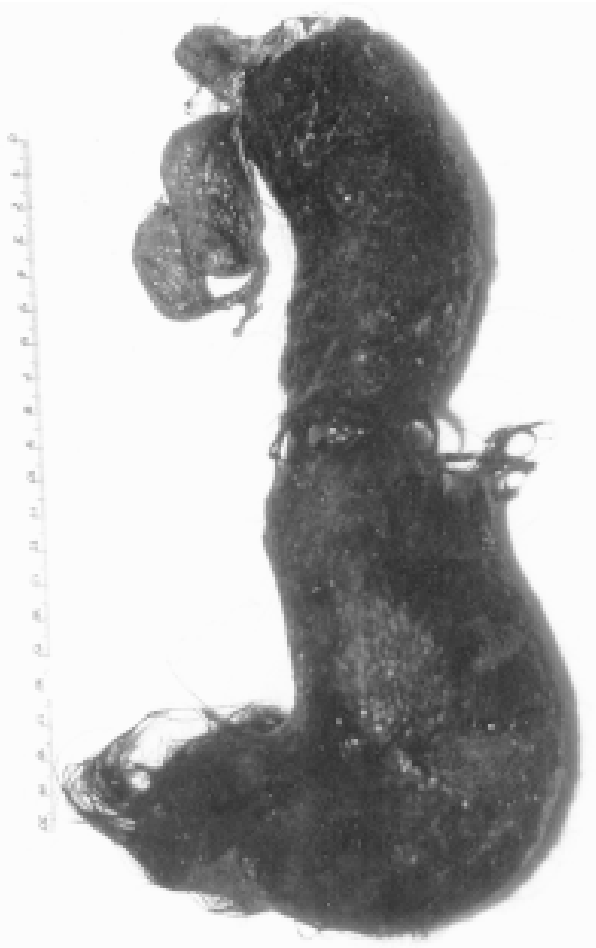

Figura 1 - Tricobezoar, pesando 820 g. e medindo aproximadamente $25 \mathrm{~cm}$. em seu maior diâmetro.

1. Cirurgião do Aparelho Digestivo do Hospital Evangélico, Hospital Mater Dei, Santa Casa de Misericórdia e Gastrocentro de Londrina - PR

2. Docente do setor de gastroenterologia da Universidade Estadual de Londrina e médica do setor de gastroenterologia do Hospital Evangélico de Londrina - PR

3. Acadêmico da Faculdade de Medicina da Fundação Educacional Serra dos Órgãos - Teresópolis - RJ

Recebido em 12/12/2002

Aceito para publicação em 29/04/2003

Trabalho realizado no Gastrocentro de Londrina - PR. 
Havia também grande lesão ulcerada gástrica interessando parte da parede posterior e da pequena curvatura do antro, com bordos pouco elevados, de aproximadamente $3 \mathrm{~cm}$ de diâmetro e fundo representado pelo pâncreas. As biópsias transoperatórias foram compatíveis com lesão benigna. Foram observados ainda edema pancreático e focos de esteatonecrose no andar superior do abdome. A evolução foi boa, e a paciente recebeu alta e encaminhamento para acompanhamento pós-operatório e psiquiátrico.

\section{DISCUSSÃO}

Os tricobezoares são mais comuns em mulheres entre 10 e 19 anos de idade ${ }^{2,3}$. Geralmente há problemas familiares. As queixas mais freqüentes são dor, desconforto, náuseas, vômitos, anorexia, emagrecimento, halitose e alopécia. No presente caso houve obstrução gástrica, úlcera terebrante e pancreatite aguda.
O diagnóstico habitualmente é realizado pela anamnese e exame físico, e pode ser complementado por radiografias, endoscopia, ultra-sonografia e tomografia nos casos mais complexos.

O tratamento pode ser conservador, através de endoscopia (extração ou fragmentação) e dissolução enzimática (papaína, celulase, n-acetil cisteína, suco de abacaxi, laser, litotripsia e jatos de água) ou cirúrgico, por videolaparoscopia ${ }^{4}$ ou laparotomia.

No presente caso o diagnóstico definitivo foi dificultado pela presença de pancreatite associada, o que constitui certa raridade ${ }^{5}$, e a indicação cirúrgica se baseou na obstrução gástrica. A pancreatite aguda foi tratada clinicamente com as medidas clássicas e a úlcera gástrica com omeprazol $40 \mathrm{mg}$ (quatro semanas) e $20 \mathrm{mg}$ (quatro semanas). A evolução foi boa tanto no pós-operatório precoce como tardio com total cicatrização da úlcera e normalização dos parâmetros pancreáticos.

\begin{abstract}
Bezoar is a foreing body whitin the digestive tract originated from ingestion of varied substances, mainly vegetal fiber or hair. We present a case of a 14-year-old girl with trichotillomania, gastric trichobezoar, gastric ulcer and acute pancreatitis. The patient was operated on for anterior gastrotomy and removal of trichobezoar, with good postoperative follow-up. We illustrate this case to emphasize the need for recognition of gastric ulcer with acute pancreatitis and surgical management.
\end{abstract}

Key Words: Bezoars; Stomach ulcer; Pancreatitis; Acute disease.

\section{REFERÊNCIAS}

1. Melo VA, Godoy AQ, Ceneviva R - Obstrução intestinal por ingestão de pedras. AMB Rev Assoc Méd Bras, 1981,27(7):203-204.

2. De Backey, Ochsner A - Bezoar and concretions: a comprehensive review of the literature with analysis of 303 collected cases and apresentation of 8 aditional cases. Surgery, 1939, 5(2):132-160.

3. Rodrigues FRA, Cruz CAT, Vianna AL - Tricobezoares no estômago, duodeno e íleo. Rev Col Bras Cir, 2000, 27(2):128-130
4. Domene CE, Anun M, Volpe P - Extração de fitobezoar gástrico por videolaparoscopia: considerações técnicas originais. Rev Col Bras Cir, 2002, 29(4):244-246.

5. Cardoso ES, Santos VR - Perfuração gástrica por tricobezoar. Rev Col Bras Cir, 1998, 25(6):430-431.

Endereço para Correspondência:

Dr. Álvaro Queiroz de Godoy

Av. Bandeirantes, 324

86010-010 - Londrina-PR 